\title{
COMPARISON OF THE USP APPARATUS 2 AND 4 FOR TESTING THE IN VITRO RELEASE PERFORMANCE OF IBUPROFEN GENERIC SUSPENSIONS
}

\author{
JOSE RAUL MEDINA*, MARIEL CORTES, ERIK ROMO \\ Departamento Sistemas Biológicos, Universidad Autónoma Metropolitana-Xochimilco, Mexico City, Mexico \\ Email:rmlopez@correo.xoc.uam.mx
}

Received: 13 May 2017, Revised and Accepted: 14 Jun 2017

\begin{abstract}
Objective: The aim of this study was the comparison of the in vitro release performance of ibuprofen generic suspensions and reference, based on the hydrodynamic environment generated by the flow-through cell method (USP Apparatus 4). Results were compared with those obtained by the use of the USP Apparatus 2.

Methods: The Advil ${ }^{\circledR}$ suspension $(2 \mathrm{~g} / 100 \mathrm{ml})$ and two generic formulations with the same dose were tested. Dissolution studies were carried out using a USP Apparatus 4 Sotax CE6 with $22.6 \mathrm{~mm}$ cells, laminar flow at $16 \mathrm{ml} / \mathrm{min}$, and pH $7.2 \mathrm{phosphate} \mathrm{buffer}$ at $37.0 \pm 0.5{ }^{\circ} \mathrm{C}$ as dissolution medium. Ibuprofen was quantified spectrophotometrically at $222 \mathrm{~nm}$. The in vitro release of the three drug products were studied using the USP Apparatus 2. The dissolution profiles of generic products were compared with the reference by model-independent, model-dependent, and analysis of variance (ANOVA)-based comparisons.
\end{abstract}

Results: The dissolution profile of the generic product A was similar to the dissolution profile of reference, only with the use of the USP Apparatus 4. The $f_{2}$ similarity factor was $>50$ and no significant differences were found with dissolution efficiency data $\left({ }^{*} \mathrm{P}>0.05\right)$. Similar results were found with the comparison of $\mathrm{t}_{50 \%}$ and $\mathrm{t}_{63.2 \%}$ values. Similar dissolution profiles between generic product A and reference were also found with ANOVAbased comparisons.

Conclusion: The flow-through cell method was adequate for study the in vitro release of ibuprofen suspensions. It is necessary to evaluate the in vivo performance of the drug products used in order to estimate the predictability of the proposed methodology.

Keywords: Dissolution studies, Flow-through cell apparatus, Generic products, Ibuprofen, Suspension, USP Apparatus 4

(C) 2017 The Authors. Published by Innovare Academic Sciences Pvt Ltd. This is an open access article under the CC BY license (http://creativecommons.org/licenses/by/4.0/) DOI: http://dx.doi.org/10.22159/ijap.2017v9i4.19926

\section{INTRODUCTION}

Ibuprofen, a poorly water-soluble non-steroidal anti-inflammatory drug (NSAID), is recommended for the treatment of moderate or acute pain. This compound is manufactured as solid oral dosage forms and suspensions. Ibuprofen suspension is widely used as antipyretic in children [1] and it is accessible for the elderly who cannot swallow easily [2]. Some ibuprofen formulations are available as generic drug products. A generic product refers to a bioequivalent product with the same quality and efficacy as the reference [3]. Generic drugs production represents savings for patients and hospitals and these formulations should be evaluated periodically. To determine whether this drug is safely interchangeable, the evaluation of their in vitro performance under conditions that simulate the natural environment of the gastrointestinal tract is very important.

According to the Biopharmaceutics Classification System (BCS), ibuprofen is a Class II drug owing to its low solubility/high permeability characteristics [4]. Class II drugs are compounds with a dissolution-limited absorption and a significant in vitro-in vivo correlation (IVIVC) should be expected using a well-designed in vitro dissolution test. The establishment of a significant IVIVC provides the basis for estimating the in vivo performance of the drug and waives the costly bioequivalence studies [5]. Previously, some researchers have reported the dissolution profiles of ibuprofen suspension using the BCS criteria [2]. Experiments were carried out with the United State Pharmacopeia (USP) paddle apparatus (USP Apparatus 2) with $900 \mathrm{ml}$ of buffer $\mathrm{pH} 7.2$, $\mathrm{pH} \mathrm{6.8,} \mathrm{pH} 4.5$, and $0.1 \mathrm{M}$ $\mathrm{HCl}$ as dissolution medium. Agitation rates of 25 and $50 \mathrm{rpm}$ were tested. The researchers observed that the higher amount of drug was released at pH 7.2 (more than $100 \%$ ) during 30 min and that 50 rpm was the adequate condition to discriminate among dissolution profiles. Nevertheless, they only studied the reference product and comparisons, at the same experimental conditions, were carried out with the in vitro release of ibuprofen tablets.
A dissolution test for ibuprofen suspensions, using the USP Apparatus 2 at $50 \mathrm{rpm}$ with $900 \mathrm{ml}$ of pH 7.2 phosphate buffer as the dissolution medium, is officially described [6]. Under these conditions, not less than $80 \%$ of the drug should be dissolved in 60 $\min (Q \geq 80 \%)$. This criterion is established to ensure the good quality of the drug products. However, previous studies have shown that despite most drug products meet the pharmacopeial dissolution criteria, some generics differed in their dissolution profiles when comparing with their branded counterparts, which questions the interchangeability between them or even among generic products [7].

The flow-through cell method (USP Apparatus 4) is an alternative apparatus for dissolution studies [8, 9]. Its advantages over the USP Apparatus 2 have been widely demonstrated, especially for the study of the in vitro dissolution performance of poorly water-soluble drugs $[10,11]$. The flow-through cell method permits continuous extraction of the drug, simulating absorption into the systemic circulation, generating an intermittent flow of the dissolution medium into the cell where the dosage form is placed [12]. It can be used as an open system, allowing release under sink conditions, which facilitates the dissolution of poorly water-soluble drugs as well as change the dissolution medium within a $\mathrm{pH}$ range of physiological relevance [13]. The USP Apparatus 4 has been used to study the in vitro release of ibuprofen from drug products manufactured in immediate-release solid dosage forms [14], and in fixed-dose combination formulations [15].

Despite the advantages of the flow-through cell apparatus over the USP paddle apparatus, little information is available on the in vitro release of ibuprofen suspensions using the USP Apparatus 4. The aim of this study was to characterize the in vitro release performance of ibuprofen from the reference and two generic formulations, using the flow-through cell method. Results obtained were compared with those found with the official USP Apparatus 2. 


\section{MATERIALS AND METHODS}

\section{Products}

Ibuprofen was purchased from Sigma-Aldrich Co. (St. Louis MO, USA). Sodium phosphate monobasic and sodium hydroxide were purchased from J. T. Baker-Mexico. The Advil ${ }^{\circledR}$ suspension (Pfizer SA de $\mathrm{CV}$, Mexico) containing ibuprofen $(2 \mathrm{mg} / 100 \mathrm{ml})$, was used. The Mexican health authorities (COFEPRIS) have established this brand as reference drug product [16]. Two generic formulations containing the same dose were also used. The assay test was performed on all drug products, according to the procedures described in the USP [6]. The limit of related compound $\mathrm{C}, \mathrm{pH}$, and density was also determined.

\section{USP apparatus 2}

The dissolution profiles of ibuprofen from generic suspensions were obtained using an automated USP paddle apparatus (Sotax AT-7 Smart, Switzerland), with a piston pump (Sotax CY7-50, Switzerland). A UV/Vis spectrophotometer with $1 \mathrm{~mm}$ flow cells (Perkin Elmer Lambda 35, USA) was used. All equipment and data generated were controlled by a specific software designed by Sotax. After 15 min of mechanical agitation and with a syringe, a sample of $1 \mathrm{ml}$ of suspension was added on $900 \mathrm{ml}$ of $\mathrm{pH} 7.2$ phosphate buffer at $37.0 \pm 0.5{ }^{\circ} \mathrm{C}$. Rotational speed of $50 \mathrm{rpm}$ was used. Sequential sampling using nitrocellulose filters (Millipore) was performed every 5 min until $60 \mathrm{~min}$, with 12 replicates. The amount of ibuprofen dissolved was determined with a standard calibration curve at $222 \mathrm{~nm}$.

\section{USP apparatus 4}

The dissolution profiles of ibuprofen from generic suspensions were obtained using an automated flow-through cell apparatus (Sotax CE6, Switzerland), with 22.6-mm cells (i.d.) and a piston pump (Sotax CY7-50, Switzerland). A UV/Vis spectrophotometer with 1 $\mathrm{mm}$ flow cells (Perkin Elmer Lambda 10, USA) was used. In all experiments, laminar flow (with a bed of $6 \mathrm{~g}$ of glass beads) was used. Deareated pH 7.2 phosphate buffer at $37.0 \pm 0.5^{\circ} \mathrm{C}$ was pumped at $16 \mathrm{ml} / \mathrm{min}$. An open system was used, without recycling the dissolution medium. After 15 min of mechanical agitation and with a syringe, a sample of $1 \mathrm{ml}$ of suspension was added into each cell. Sequential sampling using nitrocellulose filters (Millipore) was performed every 5 min until $60 \mathrm{~min}$, with 12 replicates. The amount of ibuprofen dissolved was determined with a standard calibration curve at $222 \mathrm{~nm}$.

\section{Data analysis}

The dissolution profiles of the generic drug products A and B vs. reference were compared by model-independent,-dependent and analysis of variance (ANOVA)-based methods [12, 17]. For modelindependent comparisons, the $f_{2}$ similarity factor, mean dissolution time (MDT), and dissolution efficiency (DE) were calculated. Furthermore, the percentage of ibuprofen dissolved at $60 \mathrm{~min}$ was also compared. The parameters of generic products A and B vs. reference were compared using a univariate one-way ANOVA followed by a Dunnett's multiple comparison tests. Differences were considered significant if ${ }^{*} \mathrm{P}<0.05$. For calculation of DE and MDT values, the Excel add-in DDSolver was used [18]. For all statistical comparisons, SigmaPlot software was used (version 11.0).

For model-dependent comparisons, dissolution data were fitted to Weibull, logistic, Gompertz, and probit models. The model with the highest adjusted determination coefficient $\left(\mathrm{R}^{2}\right.$ adjusted $)$ and the minimum Akaike information criterion (AIC) was chosen as the best fit model [17]. Data analysis was performed using the Excel add-in DDSolver. Additionally, dissolution data were fitted to sigmoidal model using SigmaPlot software. With this fit, the $t_{50 \%}$ and $t_{63.2 \%}$ values were calculated. The values of the generic products $A$ and $B$ $v s$. reference were statistically compared and differences were considered significant if $* \mathrm{P}<0.05$.

The ANOVA-based comparisons were carried out with the percentage of ibuprofen dissolved at each time point using a univariate one-way ANOVA followed by a Dunnett's multiple comparisons test. Differences were considered significant if $* \mathrm{P}<0.05$.

\section{RESULTS AND DISCUSSION}

All drug products met the assay test specified in the USP. The percentages of ibuprofen were between 90 and 110\% [6]. The limit of related compound $\mathrm{C}, \mathrm{pH}$, and density data are shown in table 1 .

Table 1: Characterization of ibuprofen suspensions

\begin{tabular}{|c|c|c|c|c|}
\hline Code & Assay (\%), RSD (\%) & Limit of related compound C (\%) & pH & Density $(\mathrm{g} / \mathrm{ml})$ \\
\hline $\mathrm{R}$ & $100.8,0.73$ & 0 & 4.138 & 1.2491 \\
\hline A & $97.6,0.21$ & 0 & 5.366 & 1.1702 \\
\hline B & $99.9,1.27$ & 0 & 4.133 & 1.1729 \\
\hline
\end{tabular}

RSD: relative standard deviation

\section{Dissolution profiles}

The dissolution profiles of ibuprofen suspensions are shown in fig. 1. Considering a single-point specification $(Q \geq 80 \%$ in $60 \mathrm{~min})$, all drug products met the pharmacopeial dissolution criterion using both dissolution apparatuses. It is important to note that the generic product $\mathrm{B}$ released the complete dose of ibuprofen at the first sampling time (5 min) when using the USP Apparatus 2.
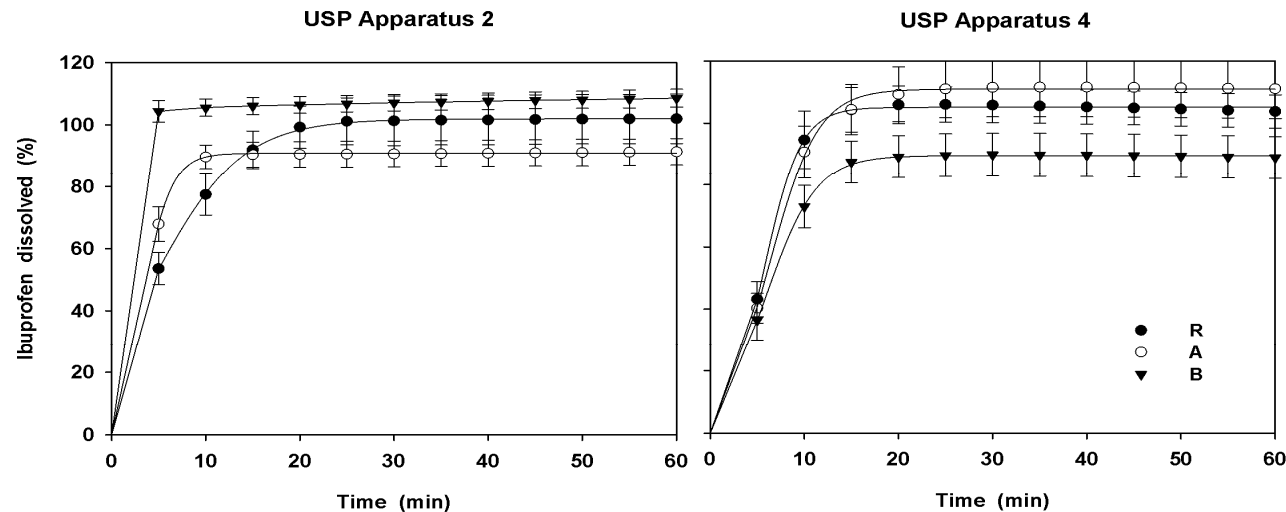

Fig. 1: Dissolution profiles of ibuprofen suspensions, $R$ ) reference and $A$ ) and B) generic products. mean $\pm S D, n=12$ 
Although all drug products met the pharmacopeial dissolution criterion, differences in dissolution profiles of both generic products $v s$. reference were found. The $f_{2}$ similarity factor of the generic products $A$ and $B$, were 49.48 and 37.98 respectively when using the USP paddle apparatus. In the same order, the $f_{2}$ values were 63.46 and 40.85 , when using the flow-through cell method. With these results, the dissolution profile of the generic product $\mathrm{A}$, was considered similar to the dissolution profile of reference $\left(f_{2}>50\right)$, only when using the USP Apparatus 4.

All drug products showed slightly slow in vitro release of ibuprofen when using the flow-through cell apparatus $(>35 \%$ dissolved in 5 $\min v s .>50 \%$ at the same time with the USP paddle apparatus). Some researchers have suggested that this result can be explained by the hydrodynamic conditions that characterize the USP Apparatus 4, which lacks an agitation mechanism, and by the fact that the dosage form and the drug particles are continuously exposed to uniform laminar flow, similar to the natural environment of the gastro- intestinal tract, causing different dissolution pattern [19]. When using the flow-through cell apparatus, cell size, glass beads, and flow rate are critical factors in determining the dissolution pattern. The flow rate of $16 \mathrm{ml} / \mathrm{min}$ is suggested by the European and USP [20]. When the flow rate of the dissolution medium is $16 \mathrm{ml} / \mathrm{min}$, the fluid flow inside the $22.6-\mathrm{mm}$ cells is $4 \mathrm{~cm} / \mathrm{min}$ [21]. Fotaki et al. [21] reported that the axial velocity of the intestinal fluid is approximately $1.5 \mathrm{~cm} / \mathrm{min}$. Therefore, the axial velocity of $4 \mathrm{~cm} / \mathrm{min}$ generated under the experimental conditions described above is close to reported physiological parameters.

\section{Model-independent comparisons}

The mean values \pm standard error of the mean (SEM) of ibuprofen dissolved at $60 \mathrm{~min}$, and model-independent parameters MDT and $\mathrm{DE}$, are shown in table 2 . In all comparisons, significant differences were observed between the dissolution profiles of the generic products $\mathrm{A}$ and $\mathrm{B} v s$. reference $\left({ }^{*} \mathrm{P}<0.05\right)$, excepting the $\mathrm{DE}$ value of the generic product $\mathrm{A}$, with the USP Apparatus $4\left({ }^{*} \mathrm{P}>0.05\right)$.

Table 2: Model-independent parameters of ibuprofen suspensions

\begin{tabular}{lllll}
\hline USP & Code & \% Diss. at 60 min & MDT (min) & DE (\%) \\
\hline 2 & R & $101.97 \pm 2.30$ & $6.81 \pm 0.17$ & $90.35 \pm 1.88$ \\
& A & $91.33 \pm 1.23^{*}$ & $4.14 \pm 0.16^{*}$ & $85.01 \pm 1.08^{*}$ \\
& B & $108.58 \pm 0.84^{*}$ & $3.36 \pm 0.10^{*}$ & $102.49 \pm 0.75^{*}$ \\
4 & R & $103.77 \pm 1.55$ & $5.28 \pm 0.21$ & $94.67 \pm 1.63$ \\
& A & $111.08 \pm 2.75^{*}$ & $6.86 \pm 0.22^{*}$ & $98.33 \pm 2.31$ \\
& B & $88.90 \pm 1.96^{*}$ & $6.12 \pm 0.25^{*}$ & $79.79 \pm 1.61^{*}$ \\
\hline
\end{tabular}

R: reference, A and B: generic products, MDT: mean dissolution time, DE: dissolution efficiency. mean \pm SEM, $n=12,{ }^{*}<<0.05$

The model-independent parameters MDT and DE are commonly used parameters to compare dissolution profiles. The MDT represents the average time at which $63.2 \%$ of the dose is dissolved, and DE relates the area under the curve of the dissolution profile to the total area of the rectangle formed, by the theoretical dissolution of $100 \%$ of the dose and the time interval of the test. The MDT and DE have been also proposed as satisfactory parameters for in vitro-in vivo correlation (IVIVC) levels B and C [22]. Level B is defined as the relationship between the MDT and mean residence time (average time that a molecule stays in the body), and both parameters are calculated by statistical moments analysis. Level $\mathrm{C}$ is defined as the association between a dissolution time point $\left(\mathrm{t}_{50 \%}, \mathrm{t}_{85 \%}\right.$, etc.) and one pharmacokinetic parameter, such as area under the curve, $\mathrm{C}_{\max }$, or $\mathrm{T}_{\max }$. The $\mathrm{DE}$ value is used by some researchers as an appropriate parameter to expresses the global drug dissolution performance, useful for comparison of dissolution profiles [23] or to relate it to some in vivo parameter.

\section{Model-dependent comparisons}

The $\mathrm{R}^{2}$ adjusted and AIC mean values for ibuprofen suspensions are shown in table 3 .

Table 3: Criteria used for the selection of the best fit model

\begin{tabular}{|c|c|c|c|c|c|c|c|c|}
\hline \multicolumn{4}{|c|}{ USP Apparatus 2} & \multicolumn{5}{|c|}{ USP Apparatus 4} \\
\hline Code & Weibull & logistic & Gompertz & probit & Weibull & logistic & Gompertz & probit \\
\hline \multicolumn{9}{|l|}{$\mathrm{R}^{2}$ adjusted } \\
\hline $\mathrm{R}$ & 0.9888 & 0.9773 & 0.9722 & 0.9813 & 0.9968 & 0.9951 & 0.9939 & 0.9965 \\
\hline$A$ & 0.9968 & 0.9973 & 0.9974 & 0.9970 & 0.9969 & 0.9991 & 0.9976 & 0.9996 \\
\hline B & 0.9460 & 0.9453 & 0.9452 & 0.9450 & 0.9901 & 0.9817 & 0.9774 & 0.9850 \\
\hline \multicolumn{9}{|l|}{ AIC } \\
\hline $\mathrm{R}$ & 33.33 & 47.04 & 50.16 & 43.21 & 28.71 & 33.85 & 37.22 & 29.26 \\
\hline A & 0.06 & -2.12 & -2.38 & -0.61 & 33.26 & 19.16 & 30.92 & 7.74 \\
\hline B & -5.56 & -5.49 & -5.46 & -5.29 & 27.12 & 33.20 & 37.18 & 29.13 \\
\hline
\end{tabular}

R: reference, A and B: generic products, AIC: Akaike information criterion. Mean, $\mathrm{n}=12$

The dissolution data of the reference and generic product $\mathrm{B}$, were well fitted to the Weibull function when using USP Apparatus 2 and 4. Both products reached the highest values of $\mathrm{R}^{2}$ adjusted and the lowest values of AIC. The dissolution data for the generic product $\mathrm{A}$ were well fitted to the Gompertz function and probit equation, when using the USP Apparatus 2 and 4, respectively. None of the ibuprofen data was well fitted by the logistic model.

The Weibull function (Eq. 1) is widely used for the study of in vitro drug release mechanisms [24]. An advantage of this model is that parameter calculation is independent of whether or not sink conditions prevail [25]. As the generic product $\mathrm{B}$ and reference were well adjusted to this function, $\beta$ parameter was used to compare the dissolution profiles. Mean data were compared by a Student's $t$-test and significant differences were found $\left({ }^{*} \mathrm{P}<0.05\right)$. The dissolution profiles of generic product $\mathrm{B}$ were considered dissimilar respect to the dissolution profile of reference, in both dissolution apparatuses.

$$
F=F_{\max }\left(1-e^{-\frac{e^{F}}{\alpha}}\right) \text { Eq. [1] }
$$

Where $\alpha$ is the scale parameter and $\beta$ is the shape parameter [18].

Because all drug products showed adequate $\mathrm{R}^{2}$ adjusted values, the Weibull parameters of the three formulations were calculated, and parameters and $T d$ values are shown in table 4 . 
Table 4: Model-dependent parameters (Weibull function) and $T d$ values

\begin{tabular}{|c|c|c|c|c|c|}
\hline USP & Code & $\alpha$ & $\beta$ & $F_{\max }$ & $T d( \pm S E M)$ \\
\hline \multirow[t]{3}{*}{2} & $\mathrm{R}$ & 8.16 & 1.08 & 102.19 & $6.81 \pm 0.22$ \\
\hline & A & 12.09 & 1.69 & 90.83 & $4.11 \pm 0.15$ \\
\hline & B & 0.47 & $0.08^{*}$ & 114.01 & $\dagger$ \\
\hline \multirow[t]{3}{*}{4} & $\mathrm{R}$ & 61.55 & 2.15 & 105.11 & $6.79 \pm 0.15$ \\
\hline & A & 43.18 & 1.84 & 111.09 & $7.70 \pm 0.20$ \\
\hline & $\mathrm{B}$ & 49.82 & $1.87^{*}$ & 89.58 & $7.27 \pm 0.25$ \\
\hline
\end{tabular}

$\alpha$ : scale parameter, $\beta$ : shape parameter. Mean, $n=12,{ }^{*} P<0.05, \dagger$ no real value was found

As in vitro release of ibuprofen from the generic product, B was fast, using the USP paddle apparatus (the complete dose was dissolved at 5 min), no real value for the $T d$ parameter was found. The $T d$ parameter is equivalent to the model-independent parameter MDT [26].

The Weibull shape parameter $\beta$ characterizes the dissolution profile as exponential $(\beta=1)$; as sigmoid S-shaped, with upward curvature followed by a turning point $(\beta>1)$; or as parabolic, with a steeper initial slope that is consistent with the exponential $(\beta<1)$ [26]. The in vitro release of ibuprofen from the three drug products showed $\beta$ values $>1$, meaning sigmoidal profiles excepting the generic product $B$ under the hydrodynamic environment of USP Apparatus 2. By the obtained results, the in vitro release of ibuprofen from suspensions seems not to be the same in the USP Apparatus 2 and 4. To confirm this result, the MDT and Td values were separately plotted by dissolution apparatus. Results are shown in fig. 2.
USP Apparatus 2

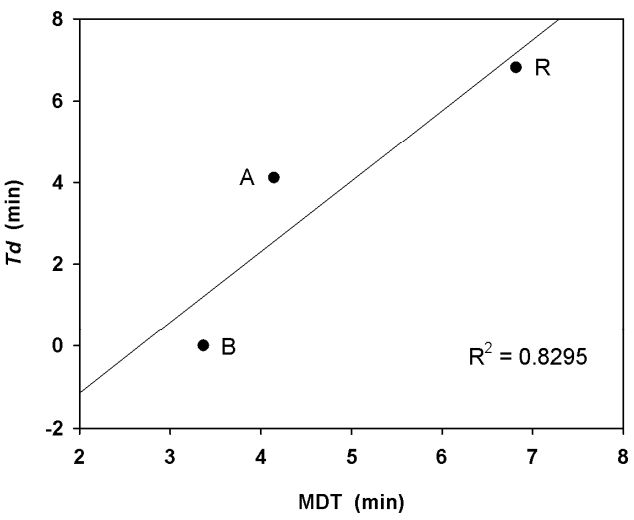

USP Apparatus 4

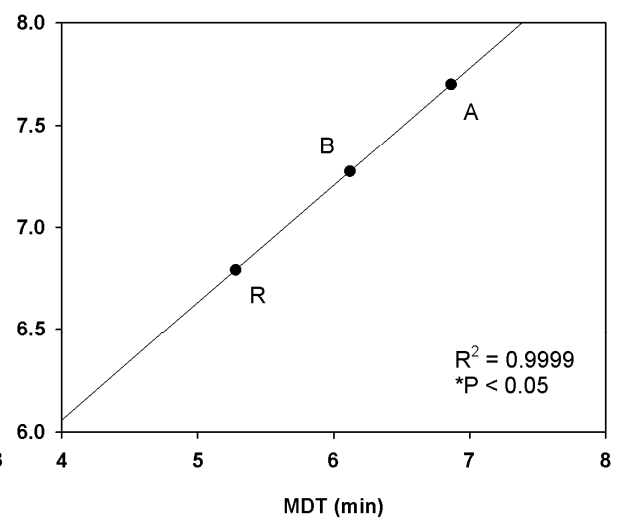

Fig. 2: Linear regression between $T d v s$. MDT values of ibuprofen from the generic products $A$ and $B$ and reference (R) Mean, $n=12$

Only linear regression of data obtained with the USP Apparatus 4 was significant $\left({ }^{*} \mathrm{P}<0.05\right)$. This results confirm that the in vitro release of ibuprofen suspensions, under the hydrodynamic environment generated by the USP Apparatus 4, is better than that generated by the USP paddle apparatus, independently of the used formulation. These results agree with previous reports of in vitro studies of ibuprofen in fixed-dose combination formulations [15].

Because an inconsistent fitting was found when using the mathematical models described above, and with almost all drug products the $\beta$ values were $>1$, the sigmoidal model (Eq. 2) was used to fit the dissolution data.

$$
y=\frac{a}{1+e^{-\left(\frac{m-x_{0}}{b}\right)}} \text { Eq. [2] }
$$

Where $a, b$ and $x 0$ are constants [18].

The data adjusted to the sigmoidal model allowed to obtain $\mathrm{R}^{2}$ values higher than 0.99 , excepting the $\mathrm{R}^{2}$ value of the generic product $\mathrm{B}$ $(>0.98)$. With $a, b$, and $x 0$ parameters, the $\mathrm{t}_{50 \%}$ and $\mathrm{t}_{63.2 \%}$ values were calculated. Data of sigmoidal model parameters and $t_{x} \%$ values are shown in table 5 .

Table 5: Model-dependent parameters (Sigmoidal equation) and $t_{x \%}$ values

\begin{tabular}{|c|c|c|c|c|c|c|c|}
\hline USP & Code & $\mathbf{R}^{2}$ & $a$ & $\boldsymbol{b}$ & $x_{0}$ & $\mathbf{t}_{50 \%}$ (min) & $\mathrm{t}_{63.2 \%}(\mathrm{~min})$ \\
\hline \multirow[t]{3}{*}{2} & $\mathrm{R}$ & 0.9954 & 101.94 & 4.54 & 4.62 & 4.45 & 6.88 \\
\hline & A & 0.9974 & 90.83 & 1.49 & 3.35 & $3.65^{*}$ & $4.58^{*}$ \\
\hline & B & 0.9843 & 109.62 & 35.23 & -98.07 & $\dagger$ & $\dagger$ \\
\hline \multirow[t]{3}{*}{4} & $\mathrm{R}$ & 0.9973 & 105.14 & 1.92 & 5.74 & 5.59 & 6.58 \\
\hline & A & 0.9973 & 111.04 & 2.51 & 6.41 & 5.92 & 7.14 \\
\hline & B & 0.9937 & 89.61 & 2.56 & 5.99 & $6.56^{*}$ & $8.21^{*}$ \\
\hline
\end{tabular}

Mean, $\mathrm{n}=12, * \mathrm{P}<0.05$, $\uparrow$ no real values were found

As the in vitro release of ibuprofen from the generic product B was fast, when using the USP Apparatus 2, no real value for the $t_{50 \%}$ and $\mathrm{t}_{63.2 \%}$ parameters were calculated. Dissolution profiles were compared with the $t_{x} \%$ values and significant differences were found $\left({ }^{*} \mathrm{P}<0.05\right)$ between the generic product $\mathrm{A} v$ s. reference (USP Apparatus 2, Student's $t$-test), and between the generic product B vs. reference (USP Apparatus 4, univariate one-way ANOVA).
The $t_{x} \%$ and sampling time values are commonly used to characterize the drug release rate. The $t_{x} \%$ value corresponds to the time necessary to release a determined percentage of drug (e. g., $\left.\mathrm{t}_{10 \%}, \mathrm{t}_{50 \%}, \mathrm{t}_{90 \%}\right)$ and the sampling time corresponds to the amount of drug dissolved in that time (e. g., $t_{10} \mathrm{~min}, \mathrm{t}_{50} \mathrm{~min}, \mathrm{t}_{90} \mathrm{~min}$ ). Pharmacopeias use this parameter as an acceptable limit for the dissolution test (e. g., $\mathrm{t}_{45 \min } \geq 80 \%$ ) [27]. 


\section{ANOVA-based comparisons}

ANOVA-based comparisons were used to compare the dissolution profiles of the ibuprofen suspensions. The advantage of this approach is that it is not restricted to any of the requirements of model-independent comparisons. Additionally, it does not depend on data fitting to a specific equation. Comparisons between the generic products $\mathrm{A}$ and $\mathrm{B} v s$. reference, when using both dissolution apparatuses, were carried out at each sampling time. Results are shown in table 6.

Table 6: Dunnett's multiple comparison tests for the percentage of ibuprofen dissolved at each time point of the generic product A and B vs. reference

\begin{tabular}{|c|c|c|c|c|c|}
\hline \multirow[t]{2}{*}{ Comparison } & \multirow[t]{2}{*}{ Time (min) } & \multicolumn{2}{|c|}{ USP Apparatus 2} & \multicolumn{2}{|c|}{ USP Apparatus 4} \\
\hline & & Difference & $* \mathbf{P}$ & Difference & $* \mathbf{P}$ \\
\hline \multirow[t]{12}{*}{ A vs. $\mathrm{R}$} & 5 & 14.31 & $<0.05$ & 2.89 & $>0.05$ \\
\hline & 10 & 12.28 & $<0.05$ & 3.92 & $>0.05$ \\
\hline & 15 & 1.57 & $>0.05$ & 0.11 & $>0.05$ \\
\hline & 20 & 8.80 & $<0.05$ & 3.37 & $>0.05$ \\
\hline & 25 & 5.60 & $<0.05$ & 4.96 & $>0.05$ \\
\hline & 30 & 10.64 & $<0.05$ & 5.67 & $>0.05$ \\
\hline & 35 & 10.73 & $<0.05$ & 6.06 & $>0.05$ \\
\hline & 40 & 10.73 & $<0.05$ & 6.36 & $>0.05$ \\
\hline & 45 & 10.72 & $<0.05$ & 6.61 & $>0.05$ \\
\hline & 50 & 10.75 & $<0.05$ & 6.83 & $>0.05$ \\
\hline & 55 & 10.72 & $<0.05$ & 7.06 & $<0.05$ \\
\hline & 60 & 10.63 & $<0.05$ & 7.30 & $<0.05$ \\
\hline \multirow[t]{12}{*}{ B vs. R } & 5 & 50.79 & $<0.05$ & 6.69 & $<0.05$ \\
\hline & 10 & 28.14 & $<0.05$ & 21.66 & $<0.05$ \\
\hline & 15 & 14.09 & $<0.05$ & 16.82 & $<0.05$ \\
\hline & 20 & 7.16 & $<0.05$ & 16.74 & $<0.05$ \\
\hline & 25 & 10.59 & $<0.05$ & 16.39 & $<0.05$ \\
\hline & 30 & 5.81 & $<0.05$ & 16.00 & $<0.05$ \\
\hline & 35 & 5.85 & $<0.05$ & 15.74 & $<0.05$ \\
\hline & 40 & 6.04 & $<0.05$ & 15.54 & $<0.05$ \\
\hline & 45 & 6.20 & $<0.05$ & 15.36 & $<0.05$ \\
\hline & 50 & 6.27 & $<0.05$ & 15.20 & $<0.05$ \\
\hline & 55 & 6.39 & $<0.05$ & 15.03 & $<0.05$ \\
\hline & 60 & 6.61 & $<0.05$ & 14.87 & $<0.05$ \\
\hline
\end{tabular}

Significant differences were found $\left({ }^{*} \mathrm{P}<0.05\right)$ at most time points excepting, the generic product A vs. reference until 50 min. when using the flow-through cell apparatus. The statistical analysis emphasized the great sensitivity and discriminative capacity of the flow-through cell apparatus in the evaluation of the in vitro release of ibuprofen suspensions in comparison to the official USP paddle apparatus.

After the application of the three methods to compare the dissolution profiles of two generic products of ibuprofen suspensions against the reference it can be observed that with the use of the USP Apparatus 2, the dissolution profiles of the generic products $A$ and $B$ were dissimilar, however, with the flow-through cell apparatus only the generic product B had dissimilar dissolution profile. The relationship of these differences with the in vivo performance has not been demonstrated yet. Because little information is available on ibuprofen suspensions under the hydrodynamic environment generated by the USP Apparatus 2 and 4 , additional research is necessary. Some authors have suggested the optimization of the flow-through cell to obtain reliable and discriminative results reflecting the formulation variables prior to bioequivalence testing [12]; as well as the in vivo bioequivalence studies for generic and brand drugs are required to be conducted to ascertain more precise therapeutic and clinical equivalence [28]. Finally, it is important to emphasize that this is the first in vitro release study of ibuprofen generic suspensions comparing the flowthrough cell method and the official USP paddle apparatus. The clinical impact of the results here obtained should be evaluated using appropriate clinical protocols.

\section{CONCLUSION}

Characterization of the in vitro release of ibuprofen suspensions using the flow-through cell apparatus revealed similarities in the dissolution rate of the generic formulation A and the reference product. Given the physicochemical characteristics of ibuprofen and the environment in which the formulations were tested, the differences found with the generic formulation B could be of clinical relevance.

\section{CONFLICT OF INTERESTS}

All authors have none to declare

\section{REFERENCES}

1. Bousfiha AA, Maaroufi A, Abid A, Tahiri S. Antipyretic activity of ibuprofen syrup in children emergency unit. J Pediatr Pueric 2003;16:407-10.

2. Rivera-Leyva JC, García-Flores M, Valladares-Méndez A, OrozcoCastellanos LM, Martínez-Alfaro M. Comparative studies on the dissolution profiles of oral ibuprofen suspensions and commercial tablets using biopharmaceutical classification system criteria. Indian J Pharm Sci 2012;74:312-8.

3. Kumar L, Deshpande A, Page A. Super generics/improved therapeutic entities: an approach to fulfilling unmet medical needs and extending market exclusivity of generic medicines. Int J Pharm Pharm Sci 2015; 7:25-9.

4. Lindenberg M, Kopp S, Dressman JB. Classification of orally administered drugs on the World Health Organization model list of essential medicines according to the biopharmaceutics classification system. Eur J Pharm Biopharm 2004;58:265-78.

5. Food and Drug Administration. Guidance for industry: Waiver of in vivo bioavailability and bioequivalence studies for immediate-release solid oral dosage forms based on a Biopharmaceutics Classification System; 2015. Available from: https://www.fda.gov/downloads/Drugs/./Guidances/ucm070 246.pdf. [Last accessed on 03 May 2017]

6. United States Pharmacopeia and National Formulary USP 40NF 35; The United States Pharmacopeial Convention, Inc: Rockville MD; 2017.

7. Al Almeri MN, Nayuni N, Anuil Akumar KG, Perrett D, Tucker A, Johnston A. The differences between the branded and generic medicines using solid dosage forms: in vitro dissolution testing. Results Pharm Sci 2012;2:1-8.

8. Singh I, Aboul-Enein HY. Advantages of USP apparatus IV (flowthrough cell apparatus) in dissolution studies. J Iran Chem Soc 2006;3:220-2. 
9. Qui S, Wang K, Li M. In vitro dissolution studies of immediaterelease and extended release formulations using flow-through cell apparatus 4. Dissolution Technol 2014;21:6-15.

10. Sunesen VH, Pedersen BL, Kristensen HG, Müllertz A. In vivo in vitro correlations for a poorly soluble drug, danazol, using the flow-through dissolution method with biorelevant dissolution media. Eur J Pharm Sci 2005;24:305-13.

11. Szymanska E, Winnicka K. Comparison of the flow-through cell and paddle methods for testing vaginal tablets containing a poorly water-soluble drug. Trop J Pharm Res 2013;12:39-44.

12. Emara LH, Emam MF, Taha NF, El-Ashmawy AA, Mursi NM. In vitro dissolution study of meloxicam immediate release products using flow-through cell (USP apparatus 4) under different operational conditions. Int J Pharm Pharm Sci 2014;6:254-60.

13. Fotaki N, Reppas C. The flow through cell methodology in the evaluation of intralumenal drug release characteristics. Dissolution Technol 2005;12:17-21.

14. Medina JR, García CA, Hurtado M, Domínguez-Ramírez AM. In vitro release study of ibuprofen dragees: dose and dissolution apparatus influence. Rev Mex Cienc Farm 2015;46:24-32.

15. Medina R, Cazares IS, Hurtado M. Domínguez-Ramírez AM. Evaluation of acetaminophen and ibuprofen in tablets by a derivative UV method: characterization of in vitro release using USP apparatuses 2 and 4. Lat Am J Pharm 2017;36:706-15.

16. Listado de Medicamentos de Referencia. Cofepris. Mexico. Available from: http://codigof.mx/medicamentos-de-referenciaactualizacion-y-lineamientos/. [Last accessed on 21 Mar 2017]

17. Yuksel N, Kanik AE, Baykara T. Comparison of in vitro dissolution profiles by ANOVA-based, model-dependent and independent methods. Int J Pharm 2000;209:57-67.

18. Zhang Y, Huo M, Zhou J, Zou A, Li W, Yao C, et al. DD solver: an add-in program for modeling and comparison of drug dissolution profiles. AAPS J 2010;12:263-71.

19. Langenbucher F, Benz D, Kurth W, Moller H, Otz M. Standardized flow-cell method as an alternative to existing pharmacopoeial dissolution testing. Pharm Ind 1989;51:1276-81.

20. Steffansen B, Brodin B, Und Nielsen C. editors. Molecular Biopharmaceutics. ULLA Pharmacy Series. Pharmaceutical Press; 2010.

21. Fotaki N, Symillides M, Reppas C. In vitro versus canine data for predicting input profiles of isosorbide-5-mononitrate from oral extended release products on a confidence interval basis. Eur J Pharm Sci 2005;24:115-22.

22. Demirtürk E, Öner L. In vitro-in vivo correlations. FABAD J Pharm Sci 2003;28:215-24.

23. Anderson NH, Bauer M, Boussac N, Khan-Malek R, Munden P, Sardaro M. An evaluation of fit factors and dissolution efficiency for the comparison of in vitro dissolution profiles. J Pharm Biomed Anal 1998;17:811-22.

24. Papadopoulou V, Kosmidis K, Vlachou M, Macheras P. On the use of the weibull function for the discernment of drug release mechanisms. Int J Pharm 2006;309:44-50.

25. Scholz A, Kostewicz E, Abrahamsson B, Dressman JB. Can the USP paddle method be used to represent in vivo hydrodynamics? J Pharm Pharmacol 2003;55:443-51.

26. Langenbucher $F$. Linearization of dissolution rate curves by the weibull distribution. J Pharm Pharmacol 1972;24:97-81.

27. Costa P, Sousa Lobo JM. Modeling and comparison of dissolution profiles. Eur J Pharm Sci 2001;13:123-33.

28. Hettiarachchi TW, Wickramaratne DBM, Sedeshika SHT, Niyangoda D, Sakeena MHF, Herath HMDR. Comparative invitro evaluation of metformin $\mathrm{HCl}$ and paracetamol tablets commercially available in Kandy District, Sri Lanka. Int J Pharm Pharm Sci 2015;7:520-4.

\section{How to cite this article}

- José Raúl Medina, Mariel Cortés, Erik Romo. Comparison of the USP Apparatus 2 and 4 for testing the in vitro release performance of ibuprofen generic suspensions. Int J Appl Pharm 2017;9(4):90-95. 